\title{
Introduction to the Special Issue: "Research and Development Progress in 3D Cadastral Systems"
}

\author{
Peter van Oosterom ${ }^{1, *(1)}$ and Efi Dimopoulou ${ }^{2}$ \\ 1 Section GIS technology, Department OTB Faculty of Architecture and the Built Environment, Delft \\ University of Technology, Julianalaan 134, 2628 BL Delft, The Netherlands \\ 2 School of Rural and Surveying Engineering, National Technical University of Athens, Iroon Polytechneiou, 9, \\ Athens 15780, Greece; efi@survey.ntua.gr \\ * Correspondence: P.J.M.vanOosterom@tudelft.nl
}

Received: 5 February 2018; Accepted: 6 February 2018; Published: 9 February 2018

The content of this Special Issue has its origin in the "5th International FIG Workshop on 3D Cadastres", organized in Athens, Greece, 18-20 October 2016 [1]; see Figure 1. The Workshop provided a further stepping stone to identifying key issues and challenges within 3D Cadastres developments, as well as exchanging ideas and solutions between scientists from academia, industry and government. After the workshop, authors of selected papers (or in some cases, two teams of authors of quite related papers) were invited to publish in this Special Issue, which is devoted to the legal, organizational and technical aspects of 3D Cadastres. Therefore, this Special Issue is the subject where practice and research meet, influence, stimulate and support each other, showing the progress in the key areas of 3D Cadastres, including the Legal framework of 3D Cadastres, Initial registration of 3D parcels, 3D data management, Visualization, distribution and delivery of 3D parcels.

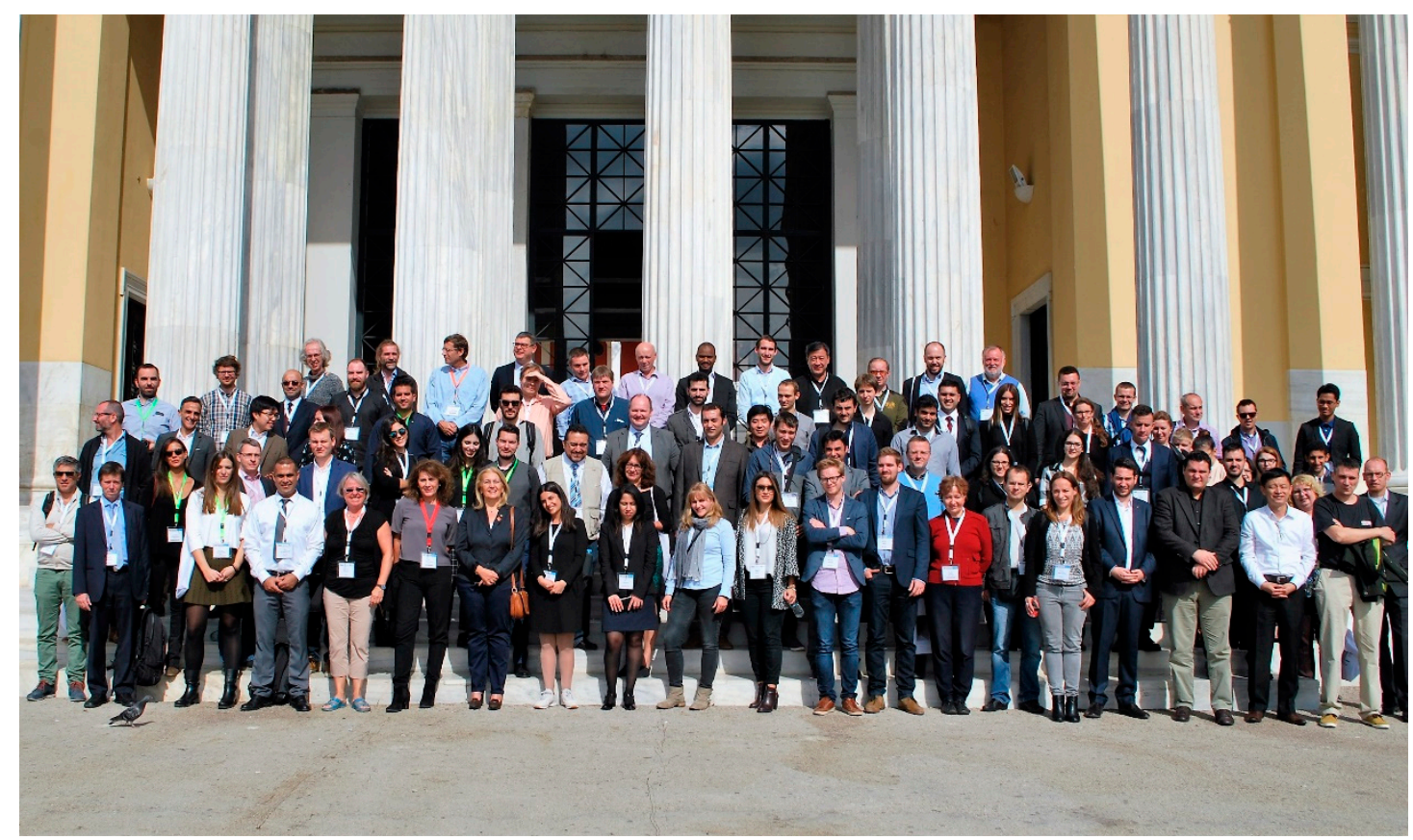

Figure 1. Participants of the 3D Cadastres workshop in Athens 2016.

Many 3D Cadastres' activities have been conducted during the past two decades: FIG 3D Cadastres workshops, sessions at FIG working weeks and congresses, and two special issues in international scientific journals [2,3] have been published. The lasting interest in 3D Cadastres and 
their progress become clear when comparing the contents of the special issues: gradually changing from more theoretical into main-stream approach for efficient and effective land administration. This special issue reflects one more step on our journey towards realizing efficient 3D cadastral registration and management.

The 13 papers published in this Special Issue are the end result of the authors' hard work and a rigorous journal's peer review process. We would like to thank the authors for their valuable contribution, and of course express thanks to the IJGI Editorial Office and the reviewers for their thoughtful suggestions and constructive criticism.

Even though all papers in this Special Issue stand on their own, depending on cultural, geographical and technical differences, we have tried to produce a rather holistic approach, covering this field of research. Moreover, we have highlighted similarities and dissimilarities in addressing important 3D Cadastral topics, as follows.

The Special Issue starts with Karel Janecka, and Petr Soucek's paper, which presents a country profile for the Cadastre of the Czech Republic, based on the ISO 19152:2012 Land Administration Domain Model (LADM). The profile considers the requirements of the new Civil Code, which explicitly considers the space above and below the ground as a part of the land. The Czech LADM-based country profile contains all of the classes and code lists required for Level 2 compliance and can be appropriately extended in order to support the registration of 3D parcels and legal components related to utilities.

The second paper, by Jantien Stoter, Hendrik Ploeger, Ruben Roes, Els van der Riet, Filip Biljecki, Hugo Ledoux, Dirco Kok and Sangmin Kim, reports on the first 3D cadastral registration of multi-level property rights in The Netherlands. Within this context, the authors present a methodology applied to two cases, representing legal volumes in an interactive 3D visualization that can be registered in the land registers. Based on the experiences of the 3D registrations of multi-level properties, as implemented in this project, it is concluded that 3D registration should be further developed, and the regulations will be adjusted accordingly.

The third paper, by Rodney James Thompson, Peter van Oosterom and Kean Huat Soon, explores the encoding of spatial units highlighting their 2D extent and topology, while fully defining their extent in the third dimension. The paper presents a conceptual model applied to topology encoding of range of spatial units (2D, simple 3D, complex 3D), expressed in the language of the LADM. Especially in the case of larger apartment buildings, there are many boundary surfaces shared between neighboring 3D parcels, which makes 3D topology very appropriate. Two multi-step real-world examples are given and encoded according to this conceptual model in LandXML for exchange purposes, including the initial registration.

The fourth paper, by Dimitrios Kitsakis and Efi Dimopoulou, investigates public law restrictions (PLR) applying to 3D space along with the current legal framework. A Greek case study concerning the establishment of a subway station is examined, focusing on public utilities, archaeological legislation, and building regulations. Relative legal documentation is compiled and mapped in a 3D PLR model, presenting inefficiencies and malfunctions that can be resolved if PLRs are addressed within a 3D cadastral context.

The fifth paper, by Katerina Athanasiou, Michael Sutherland, Christos Kastrisios, Lysandros Tsoulos, Charisse Griffith-Charles, Dexter Davis and Efi Dimopoulou, addresses the 3D character of marine spaces and proposes the application of the Land Administration Domain Model (LADM conceptual standard ISO 19152) to specific jurisdictional MAS or MC, taking into account the S-121 Maritime Limits and Boundaries (MLB) Standard, which refers to LADM. Several modifications are proposed, including e.g., the introduction of class marine resources into the model, to meet the particular marine and maritime administrative needs of both Greece and the Republic of Trinidad and Tobago.

The sixth paper, by Behnam Atazadeh, Abbas Rajabifard and Mohsen Kalantari, investigates the performance of three BIM-based methods, namely purely legal, purely physical and integrated approaches, for storing, managing and communicating legal interests mainly in multistorey buildings 
in Victoria, Australia. One finding was that interaction tasks were easier to perform in purely legal or physical models compared to integrated models, while on the other hand, integrated models provide a more visual communication of the location of legal boundaries, indicating that lay users may find it easier to understand their legal rights in integrated BIM models.

The seventh paper, by Nikola Vučić, Miodrag Roić, Mario Mađer, Saša Vranić and Peter van Oosterom, explores Croatian registration related to 3D Cadastral cases, specific interests in strata and rights or restrictions related to spatial planning. Together with the analysis of the current land administration system, this forms the basis for the possible 3D upgrade. Further, the efficiency of implementation and reuse of existing data are considered; e.g., the signs or symbols as used to represent topographic objects on 2D maps (for tunnels, bridges, overpasses, etc.) as these provide a reference context for a 3D Cadastre. The authors propose the establishment of a 3D Multipurpose Land Administration System as the most efficient system of land administration, given the growing 3D data acquisition possibilities and the changing demands, the traditional real estate register is facing.

The eighth paper, by Aleksandra Radulović, Dubravka Sladić and Miro Govedarica describes the development of the Serbian Cadastral Domain Model, as an important step towards the realization of a 3D Cadastre. The proposed model is based on LADM, after analyzing national legislation (and its current incorrect application) and is completely conformant at the medium level (or even higher in some cases). Given the importance of the 3D aspects, such as buildings with sometimes overlapping rights and restrictions, the Serbian country profile uses a 2D representation for simpler situations, and a 3D representation for more complex situations.

The ninth paper, by Eftychia Kalogianni, Efi Dimopoulou, Wilko Quak, Michael Germann, Lorenz Jenni and Peter van Oosterom tries to close the gap between the conceptual model and the actual implementation of the 3D Cadastre, by using the INTERLIS language. This approach allows the inclusion of both the legal 3D spaces, the physical 3D objects (reference objects) and their relationships in a vendor-neutral manner, among others, by using formal constraints and structured code lists. The approach is LADM-based and supports, with the help of INTERLIS tools, the evaluation and validation of 3D legal and physical models. The first results of a Greek case study are presented.

The tenth paper, by Jennifer Oldfield, Peter van Oosterom, Jakob Beetz and Thomas Krijnen, also addresses steps towards implementation of 3D Cadastres. In this paper, the Open Building Information Models (BIM) standards are explored. First of all, by (re)using the available and future data in the BIM Industry Foundation Classes (IFC) as a source for 3D legal spaces. Further, the workflow of the multi-actor processes involved when planning, designing, creating and registering results of new spatial developments are organized according to BIM methodology of the Information Delivery Manual (IDM ISO29481). The proposed BIM IDM approach is used to illustrate how much time and effort are saved (and consistency is enhanced) compared to traditional registration of 3D spatial units in the land administration.

The eleventh paper, by Trent Gulliver, Anselm Haanen and Mark Goodin outlines an approach for turning the 150-years-old New Zealand cadastral survey and tenure systems into a full 3D digital Cadastre supporting 3D RRRs (rights, restrictions and responsibilities). The whole chain of activities is addressed from survey/data capture and validation, via their lodging at the authorities and integration with existing data, to visualization and dissemination. The approach of integration of 2D (default) and 3D (when needed) is promoted by regulators of New Zealand's cadastral survey system. However, given the generic nature of the proposed solution and the involvement of the suppliers of land administration systems, it is believed that other jurisdictions may also benefit from these efforts.

The twelfth paper, by Abdullah Alattas, Sisi Zlatanova, Peter van Oosterom, Efstathia Chatzinikolaou, Christiaan Lemmen and Ki-Joune Li proposes the combined use of IndoorGML and LADM Models. The main application of IndoorGML is to support indoor navigation via 3D primal (actual spaces in building) and dual (connectivity between spaces) representations. However, the actual access rights are not yet included and LADM's capabilities for describing these are applied. The access rights are dependent on the specific user/party (group), spatial unit (location) and time. 
Then, together with the 3D model of the building, this allows path computation based on access rights avoiding the non-accessible spaces. The two original standard models remain independent, and their combined use could also support other applications, such as regular building maintenance, facility management work, crisis management/evacuation, etc.

The thirteenth and last paper, by Ruba Jaljolie, Peter van Oosterom and Sagi Dalyot addresses the needed functionalities for 3D Land Management Systems with the capacity to handle various types of data in a uniform way, both above-terrain and below-terrain. Starting with the legal and technical aspects of Survey of Israel's CHANIT (legal set of cadastral work processes' specifications), the authors propose a data structure/model, functionality, and suggestions for closing the regulation gaps for a 3D Cadastre, including those needed for the preparation of 2D and 3D mutation plans (survey plans).

Concluding, we hope the cognitive 3D Cadastres community will find this Special Issue to be a useful collection of papers, to provide an informative foundation to further research in this challenging field. In the meantime, also, the next step on our on-going journey is planned: the 6th International FIG Workshop on 3D Cadastres, to be organized in Delft, The Netherlands, 2-4 October 2018.

Conflicts of Interest: The authors declare no conflicts of interest.

\section{References}

1. Van Oosterom, P.; Dimopoulou, E.; Fendel, E. (Eds.) Proceedings "5th International Workshop on 3D Cadastres"; FIG: Copenhagen, Denmark, 2016.

2. Lemmen, C.; van Oosterom, P. 3D Cadastres. Comput. Environ. Urban Syst. 2002, 27, 337-343. [CrossRef]

3. Van Oosterom, P. Research and development in 3D cadastres. Comput. Environ. Urban Syst. 2013, 40, 1-6. [CrossRef]

(c) 2018 by the authors. Licensee MDPI, Basel, Switzerland. This article is an open access article distributed under the terms and conditions of the Creative Commons Attribution (CC BY) license (http://creativecommons.org/licenses/by/4.0/). 